CATALAN REVIEW

Catalan Review

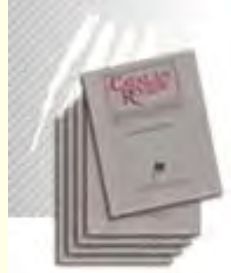

You are accessing the Digital Archive of the Catalan Review Journal.

By accessing and/or using this Digital Archive, you accept and agree to abide by the Terms and Conditions of Use available at http://www.nacs-

catalanstudies.org/catalan_review.html

Catalan Review is the premier international scholarly journal devoted to all aspects of Catalan culture. By Catalan culture is understood all manifestations of intellectual and artistic life produced in the Catalan language or in the geographical areas where Catalan is spoken. Catalan Review has been in publication since 1986 .
NORTH

AMERICAN

CATALAN

SOCIETY
Esteu accedint a l'Arxiu Digital del Catalan Review

A l' accedir i / o utilitzar aquest Arxiu Digital, vostè accepta i es compromet a complir els termes i condicions d'ús disponibles a http://www.nacs-

catalanstudies.org/catalan_review.html

Catalan Review és la primera revista internacional dedicada a tots els aspectes de la cultura catalana. Per la cultura catalana s'entén totes les manifestacions de la vida intel lectual i artística produïda en llengua catalana o en les zones geogràfiques on es parla català. Catalan Review es publica des de 1986.

Sobre el Blaquerna, la clerecia i una obra misteriosa Albert Soler i Llopart

Catalan Review, Vol. IV, number 1-2 (1990), p. 263-277 


\section{SOBRE EL BLAQUERNA, LA CLERECIA \\ I UNA OBRA MISTERIOSA}

\section{ALBERT SOLER i LLOPART}

Per als qui ens interessem per l'expressió i els recursos literaris en l'obra de Llull, pel seu ús, el seu desenvolupament o el seu significat, és especialment enutjós un buit informatiu que deixen les fonts entre els anys I274 i I287. Tretze anys! La falta de documentació és gairebé total entre 1276 i 1287, sobre els quals la Vita coaetanea fa mutis. I només cal que pensem el que un any li donava de si al beat.

El cas és que en aquest temps es concentra un seguit d'obres cabdals que es basen en el llenguatge literari: abans de final de I 276, ha escrit el Llibre del gentil, el Llibre de l'orde de cavalleria i la Doctrina pueril $;{ }^{\mathrm{T}}$ possiblement el $\mathrm{I}_{2} 8_{3}$, a Montpeller, estava escrivint (o ja acabant) el Llibre d'Evast e Blaquerna. ${ }^{2}$

${ }^{\mathrm{I}}$ Les tres obres pertanyen al primer cicle de l'Art, que gira al voltant de l'Art abreujada d'atrobar veritat. Van ser escrites després d'aquesta obra (I274) i sembla que abans de 1276 ; només podem precisar que el tractat sobre els cavallers precedeix la Doctrina pueril perquè aquesta l'esmenta. Per al Gentil veg. A. Bonner, "Problemes de cronologia lul-liana», a Estudios Lulianos, vol. 2I, Palma, 1977, pàgs. $35-38$ i 44; per a la Doctrina pueril, veg, del mateix autor, "Modificacions al catàleg d'obres de Ramon Llull", a Estudios Lulianos, vol. 26, Palma, 1986, pàgs. 82-83; recentment, E. Blanco Gómez, «La fecha de composición de la Doctrina pueril", a Estudios Lulianos, vol. 29, Palma, 1989, pàgs. I47-1 54 , ha proposat un terme a quo de març de 1275 amb uns arguments no gaire convincents. Quant al Llibre de l'orde de cavalleria veg. l'estudi preliminar a l'edició crítica preparada per mi mateix, Els Nostres Clàssics (ENC), núm. I27, Barcelona, 1988, pàgs. 9-10.

${ }^{2}$ Pel que fa a la controvertida data del Blaquerna, també és Bonner qui ha fet una de les darreres aportacions, «Sobre la data de Blaquerna», a Esctudios Lulianos, vol. 26, Palma, 1986, pàgs. I43-147; l'autor sospesa totes les dades de la discussió i creu que la data més probable de redacció de tota l'obra és $1_{2283}$; subscric aquesta conclusió. 
D'aquests anys, n'hem obtingut dades a través, principalment, de les mateixes obres; dels estudis de datació i de periodització, que ens acosten cada cop més al desenvolupament intern de l'opus lul·lià. ${ }^{3}$ La lectura capil-lar, minuciosa, exhaustiva, relacional, dels textos encara ha de donar resultats importants. També la moderna crítica textual i la codicologia aplicades a l'estudi de tots els testimonis que ens han pervingut d'una obra (escrits en qualsevol llengua, antics o moderns) poden aportar molta més informació de la que fins ara hem obtingut.

$\mathrm{El}$ present treball intenta aclarir un petit enigma sobre una obra presumptament escrita pel beat en aquells anys foscos. De retop, tanmateix, ens haurem de plantejar la manera com Llull desenvolupa un tema al llarg del temps.

Tot comença amb una referència que trobem al final del $\mathrm{Lli}$ bre de l'orde de cavalleria:

E cor nós avem a perlar del libre qui és de l'orde de clerecia, per aysò perlam tant breument del Libre de l'orde de cavaylaria, lo qual és fenit a glòria e benedicció de nostre senyor Déus. ${ }^{4}$

La pressa de Llull per acabar el llibre devia ser relativa perquè el cert és que d'aquest Llibre de l'orde de clerecia no n'hem sabut res més: o l'hem perdut o no el va arribar a escriure mai. Al mateix opuscle hi ha dos altres esments a la brevetat amb què tracta el tema dels cavallers ${ }^{5} \mathrm{i}$ això fa pensar que el problema és que al beat li reca dedicar més temps a la cavalleria, de la qual ja ha dit tot el que havia de dir. ${ }^{6}$

${ }^{3}$ Sobre ambdós aspectes són remarcables els treballs d'A. Bonner, fins a cert punt condensats a les seves Obres selectes de Ramon Llull, Palma de Mallor$\mathrm{ca}, 1989$. Al primer volum, pàgs. $58-60$, podeu trobar l'esquema de la periodització; al segon volum, pàgs. 539-589, un catàleg cronològic de les obres de Llull, el més complert $i$ correcte de tots els que $s$ 'han fet.

4 Ed. cit., pàg. 221 , paràgr. 9.

5 Ibidem, pàgs. 188 (paràgr. 36 ) i 200 (paràgr. 13 ).

${ }^{6}$ En un passatge de l'Arbre de ciència, a Obres de Ramon Llull (ORL), 
Llull va escriure, però, un Liber clericorum que, de vegades, $s^{\prime}$ ha identificat amb aquest suposat Llibre de l'orde de clerecia.? Mateu Obrador és potser el primer que s'adona que el tractat llatí que Llull va escriure a Pisa el maig del ${ }_{3} 308$ i que va adreçar a la Universitat de París, no pot ser l'esmentat a l'èxplicit de l'opuscle sobre els cavallers:

Designat algunes voltes així [Liber clericorum], y altres més laconicament encara amb el simple títol de Clericus, el compendiós doctrinari que en tercer lloch del present volum estampam, no es en rigor y si bé's repara, un tractat del «orde de Clerecían, pensat y escrit paralelament al del Orde de Cavallería y que amb aquest pogués apariarse y fer-hi joch o pendant. No hi escriu l'autor ni hi tracta de la clerecía considerada com a organisme social, com a classe o estament, senyalant-li son orígen, categoríes y preeminencia, sos drets y devers, autoritat y missió, tal com ho fa quan tracta dels cavallers. Es més tòst un senzill breviari d'ensenyament catequístich, destinat als clergues més ignorants (rudioribus) d'aquell temps $[\ldots]^{8}$

El Llibre de l'orde de clerecia no apareix al catàleg de l'Electorium, de l'agost de I3 I I, que conté la col-lecció de llibres de la Cartoixa de Vauvert; és a dir, hi figura un Liber clericorum, que hem d'identificar amb el tractat pisà. $\mathrm{Al}$ catàleg de Thomas Le

Palma de Mallorca, 1918, vol. XIII, pàg. 164, el beat lamenta que ningú hagi escrit un "libre de la art de cavallería»; hem d'entendre la referència com una queixa pel poc ressò que havia tingut el seu tractadet, on ja demanava que hom escrivís un tal llibre (veg. pàgs. 170-171, paràgr. 14 i is). Això revela també la poca importància que Llull concedia al seu opuscle sobre els cavallers.

$7 \mathrm{~J}$. Stöhr afirma que es tracta de la mateixa obra i a més sosté, per una inexplicable confusió, que hi ha una versió francesa del Llibre de l'orde de clerecia, publicada per M. Obrador al primer volum de les $O R L$; en realitat, la versió francesa és del Llibre de l'orde de cavalleria; veg. «Literarkritisches zur überlieferung der lateinische werke Ramon Llulls», a Estudios Lulianos, vol. I, Palma de Mallorca, 1957. Pere Bohigas diu en la seva edició de l'opuscle sobre els cavallers: «El llibre de l'Orde de Clerecia no s'ha conservat en català. Es conserva en llatí el Liber clericorum (...)", a Obres essencials, vol. I, Barcelona, I957, pàg. 545 , nota 27.

${ }^{8}$ M. Obrador, "Pròlech» a ORL, vol. I, Palma de Mallorca, pàg, xxxiv. 
Myésier tampoc no s'hi registra. ${ }^{9} \mathrm{Al}$ s inventaris de l'escola lul-liana de Barcelona s'hi esmenten cinc exemplars del Liber clericorum (dos al de vers 1466 , i tres al de 1478 ). ${ }^{10}$ A l'inventari de Charles de Bouvelles hi trobem només el Liber clericorum, amb el número 6r. ${ }^{\text {II }}$ Resumint: res, fora de la citació a l'opuscle esmentat. ${ }^{12}$

Hi ha motius, doncs, que fan pensar que Llull no va arribar a escriure el Llibre de l'orde de clerecia. Però hi ha una altra explicació possible d'aquest petit misteri.

De fet, el beat sí que va escriure un llibre de l'orde de clerecia més o menys coetàniament al llibre dels cavallers. Efectivament, el Llibre d'Evast e Blaquerna és sobretot un llibre de l'orde de clerecia. ${ }^{13}$ Llull hi narra la reforma d'aquest orde,

9 Vegeu el primer catàleg a Raimundi Lulli Opera Latina, VIII, Brepols, 1980, pàgs. 304-309; ambdós catàlegs a J.N. Hillgarth, Ramon Lull and lullism in fourteenth-century France, Oxford, 1971, pàgs. 335-347.

to $\mathrm{F}$. de Bofarull, «El testamento de Ramón Llull y la escuela luliana en Barcelonan a Memorias de la Real Academia de Buenas Letras, vol. V, Barcelona, 1896, pàgs. 435-479.

${ }^{11}$ Veg. J. M. Victor, «Charles de Bovelles and Nicholas de Pax: Two Sixteenth-century Biographies of Ramon Llulln, a Traditio, núm. 32, 1976, pàgs. 313-345.

${ }^{12}$ Modernament, el títol continua apareixent en diversos catàlegs d'obres del beat, com a llibre perdut. Veg. per exemple, Glorieux, Répertoire des maittres en théologie de Paris an XIII siècle, París, 1934, amb la sigla «ij»; A. Llinarès, Ramon Llull, Barcelona, 1968, núm. 133; J. Perarnau, «Inventari d'obres lul.lianes en català», a Els manuscrits lul lians medievals de la «Bayerische staatsbibliotbek» de Munic, Barcelona, 1982, núm. 15. De fet, ja el pare Antoni R. Pasqual a les seves Vindiciae Lullianae, vol. I, Avinyó, 1778, pàg. 369, el catalogava dins l'any 1275 . J. Custurer a les seves Disertaciones históricas del culto inmemorial del B. Raymundo Lulio, Mallorca, 1700 , pàg. 164 , registra a la biblioteca de La Sapiència l'existència d'un Liber de militia Clericali. Impraessus que no pot ser sinó l'edició del Liber clericorum (París, 1499).

${ }^{13} \mathrm{E}$. W. Platzeck ja va suggerir que aquest Llibre de l'orde de clerecia podria ser la part més extensa del Blaquerna: «Das Buch, "Orde de clerecia", das zum Schluß von 37-ordcav versprochen wird, ist meines Erachtens der größe Teil von 44-blaque (...)"n, a Raimund Lull, vol. II, Düsseldorf i Roma 1964, pàg. I2*, 
de l'Església i, en fi, de tota la cristiandat, a través de la trajectòria vital del protagonista, que ascendeix per la jerarquia eclesiàstica fins el seu cim (fins al summe pontificat!) i escull aleshores la via de màxim perfeccionament, l'eremitisme. L'èxplicit de la novel-la ho diu ben clarament:

Acabat és lo romanç de Evast e Blanquerna, qui és de vida de matremoni e del orde de clereçia, per donar doctrina con deja hom viure en est món per tal que en l'altre eternalment sia en glòria de Déu. ${ }^{\mathrm{I}}$

El primer llibre, «de matrimoni» explica la vida d'Evast i Aloma, els pares de Blaquerna, que juguen un paper fonamental en la correció del medi urbà en què viuen i que assoleixen la màxima perfecció possible dins l'orde de matrimoni, primer com a pares, després en la continència sexual.

Natana, al «libre de l'orde de les dones», ateny el màxim que és donat a una dona: la vida de religió i la funció de govern com abadessa, des de la qual reforma l'orde religiós femení. La seva mare, Nastàsia, aconsegueix la màxima perfecció com a dona viuda que no entra en l'estament religiós. ${ }^{\text {is }}$

El Blaquerna narra, per tant, els punts de perfecció màxima a què poden aspirar d'una banda els laics $\mathrm{i}$, de l'altra, els religiosos, dones o homes. La utopia que el beat descriu en el llibre es fonamenta, com és evident, en el caràcter genèric dels personatges, dels llocs i de les accions; els noms estranys dels personatges, la indeterminació més absoluta quant al temps i l'espai (tret de Roma, és clar), que remeten als del roman, tenen una funció tipificadora; el monestir que reforma Blaquerna significa tots els

També Bonner ha dit que l'esment al tractat sobre els cavallers podria referir-se a "un capítol" del Blaquerna, veg. "Problemes de .... op. cit., pàg. 44. La meva hipòtesi, doncs, té una part de deute amb Platzeck i Bonner.

${ }^{14}$ Llibre d'Evast e Blanquerna, ed. S. Galmés, Barcelona, ENC, 1935-1957, vol. III, pàg. 185 .

Is La referència és breu però clara, vol. I, pàg. ${ }_{3} 8$. 
monestirs d'homes, el que esmena Natana, tots els de dones, etc. Adonem-nos que el llibre presenta un esquema imaginari que entén la societat dividida entre clerici i laici. Aquesta concepció, encara que podia ser un lloc comú, prové en darrer terme de la ideologia gregoriana, de la profunda reforma que va plantejar el papa Gregori VII (1073-1085). En el seu pla, importa destacar: la pretensió del papa de sotmetre l'imperium al sacerdotium, que el va portar a un enfrontament violent amb l'emperador Enric IV; la voluntat d'alliberar l'Església de la subjecció del poder temporal a tots els nivells (des del papat als més simples clergues); la lluita contra la simonia i el matrimoni dels clergues, mesures adreçades també a enfortir la independència de la clerecia. Es tracta d'un moviment restaurador, que vol reconduir l'Església als seus orígens sota la direcció del summe Pontífex. ${ }^{16}$

Llull expressa de la següent manera una distinció que s'hi assembla: ${ }^{77}$

${ }^{16}$ J.N. Hillgarth assenyala: «In Lull's political theory, if it deserves such a high-sounding name, one finds an emphasis on the position of the papacy in Christendom that would have been eminently respectable in a theocratic contemporary of Gregory VII or even of St. Bernard but that astounds one in a man who had seen the events of Anagni, the humiliation of Boniface VIII, and the triumph of Philippe le Beln., op. cit., pàg. $\{2$. Es ben evident el caràcter teocràtic de la reforma que el beat planteja al Blaquerna i la funció que hi juga el Papa. D'altra banda, em sembla que no ha estat estudiada la influència, més o menys directa, que les idees gregorianes han pogut tenir en Llull.

${ }^{17}$ Com se sap, l'únic manuscrit en català del Blaquerna és el conservat a Munic (Hisp. [cat] 67), que és acèfal, això és, que no conté els primers folis de la novel.la. S. Galmès va suplir aquesta deficiència en la seva edició prenent el fragment inicial de l'edició catalana de 1521 ; els problemes d'infidelitat respecte a l'original que presenta aquesta edició són ben coneguts. Es més rigorós llegir l'inici directament de la versió francesa del Blaquerna, del manuscrit de París fr. 24402, datat de final del segle xuI o principi del xrv. Aquest còdex va ser editat per A. Llinarès, R. Lulle, Livre d'Evast et de Blaquerne, París, 1970, el passatge és de la pàg. 37. R. Brummer proposava reconstruir el text original a partir del text francès; veg. "Problemes textuals del "Libre de Blanquerna" de Ramon Llull», a Studia Lullistica. Miscellanea in bonorem Sebastiani Garcias Palou, 
MMout fu Evast desirré en la cité d'aucuns homes de relygion et d'aucuns homes seculiers qui desirroient estre ses parenz par maniere de mariage. Tandis con Evast estoit requis des religieus que il entrast en relygion et des seculiers que il se mariast, il pensa une nuit en l'ordre de religion et en l'ordre de mariage; et quant il ot bien pensé es condicions de ces «ijij» ordres, en volenté li vint que il entrast en relygion porce que il eschivast les vains deliz de ce monde. Puis aprés, pensa es granz richeces que son pere li avoit lessiees et coment il estoit en grant soussi de maintenir le grant ostel et la grant aumosne que son pere maintenoit en sa vie; et par ces resons et par ce meesmement car il estoit chief de son lignage, il s'enclina a mariage, et proposa que quant il seroit en l'ordre de mariage que il donast doctrine a ceus qui seroient en l'ordre de mariage.

Aquesta ideologia comporta una altra distinció: castedat-unió conjugal. La divisió dels dos ordes és d'arrel sexual. Diu Georges Duby al respecte:

Dans sa profondeur, la césure entre les deux «ordres» est perçue comme de nature sexuelle. Tous les clercs doivent être sans femme. La loi divine leur impose cette règle. Pour que le laïcat puisse lui-même s'ériger en ordre, il doit suivre également une règle, symétrique, donc portant sur la sexualité. La règle des laïcs est d'avoir des femmes - legitimes: de se marier. ${ }^{18}$

Llull, en el model d'Evast i Aloma, defineix amb un cert detall l'orde de matrimoni; entre els diversos passatges que podem assenyalar, destaca especialment la seva disputa. Evast pretén abandonar el matrimoni i entrar a formar part d'algun ordre religiós; a primera vista, el fet podria ser lloable pel que té de desig de santificació (si fa no fa, aquest és el camí que Llull mateix va triar). Tanmateix, en el contrast, Aloma li recorda fins a quin punt es deu a l'orde a què Déu l'ha destinat i l'oportunitat $i$ l'obligació que té mitjançant aquest d'acomplir la primera intenció de tota criatura: amar, servir i lloar Déu. ${ }^{\text {t9 }}$

Palma de Mallorca, 1989, pàgs. I1-13; la idea només es pot dur a terme en una edició divulgativa de la novel.la.

${ }^{18}$ Georges Duby, Les trois ordres ou l'imaginaire du féodalisme, París, 1978 , pàg. 257.

19 És el capítol IV del primer llibre. 
Però la idea de l'orde de matrimoni és portada fins a les seves darreres conseqüències un cop Blaquerna ha deixat els seus pares:

Evast e Aloma foren en la capella, aprés la missa, parlant longament de l'estament de lur vida; e ordenaren e scriviren qual regla deguesen tenir tots los jorns de lur vida, la qual regla és aquesta. En lo començament fo feet ordenament que a un feel religiós, frare lech, comenasen tots lurs béns, ençeptat tota lur messió, e que tot lo sobrepús de la renda fos donada a los pobres de Crist. Humils vestiments haguessen; «:iii'» jorns de la setmana menjassen carn; no vestisen li ni jaguesen en lançols; no's coneguessen en los carnals delits; a les matines se levasen e lurs ores diguessen; aprés la missa en oració steguessen e de Déu parlassen; ans que menjasen deguessen lavar los peus a «xxiii"» pobres, a la taula dels quals menyasen; no exissen de l'alberch a la nit; encherchasen en lur conciència si haurien errat contra Déu ni contra lur regla, e que la « i’» donàs disciplinas a l'altre, acusant-se de sa colpa. Aquesta és la regla que Evast e Aloma prengueren. ${ }^{20}$

També hi ha el debat entre Natana i la seva mare Nastàsia sobre quin dels dos ordes és més honrat i millor, si el de clerecia o el de matrimoni. ${ }^{21}$

Generalment, la bipartició gregoriana s'associa a una jerarquia de mèrits expressada en la següent tríada: els verges són superiors als continents i els continents als cònjuges.$^{22}$ Els protagonistes de la novellla són verges, continents i cònjuges: Evast i Aloma són cònjuges inevitablement perquè la missió de l'orde matrimonial és la procreació, però són continents per la pròpia voluntat d'atènyer un grau més alt en aquesta jerarquia de mèrits. Blaquerna $i$ Natana són verges, i es mantenen en el nivell més alt de virtut malgrat alguna temptació. Fora ja del romanç, en aquell artifici literari tan sorprenent que trobem al darrer capítol, Llull presenta les dues figures més altes de la cristiandat, una laica, l'emperador, i l'altra religiosa, el Papa, que es retroben en l'estament de vida eremític: l'un en la continència i l'altre en la virginitat; aquest

\footnotetext{
${ }^{20}$ Vol. I, pàgs. 91-92.

${ }^{21}$ Es tracta del capítol XIX.

${ }^{22}$ Veg. Duby, op. cit., pàgs. 257 i 309-3 10.
} 
joc estructural fa més evident encara que l'assumpte de lá novel.la és l'orde de clerecia.

Segons que hem vist $\mathrm{i}$ d'acord amb la seva mateixa estructura, en el Blaquerna, Llull no considera la societat des del punt de vista de la ideologia dels tres ordes: els que preguen, els que combaten, els que treballen; sinó que la concep bipartida entre clergues i poble, els que són castos i els que s'aparellen. Hi ha una raó immediata: el llibre postula una reforma moral de la societat.

Per exemple al Llibre de l'orde de cavalleria, Llull exposa una visió tripartida de la societat:

Molts són los officis que Déus ha donats en est món a ésser servit per los hòmens; mas, tots los pus nobles, los pus honrats, los pus acostats dos officis qui sien en est món, és offici de clergue e offici de cavalyer; per aysò, la major amistat que sia en est món deuria ésser entre clergue e cavayler. ${ }^{23}$

Diu a la primera part de l'opuscle:

E cové que les gents aren e caven e traguen mal per ço que la terra leu los fruyts on viva cavaller e ses bèsties; e que cavayler cavalc e senyoreig e haja benanança d'aquellas coses on sos hòmens hian maltret e malenança. ${ }^{24}$

En aquest opuscle, el beat desenvolupa una aplicació de la moral a l'ofici concret del cavaller, una ètica d'ofici; sobretot a la part VI, on tracta de les virtuts seguint l'esquema de l'Art abreujada. ${ }^{25}$ L'exercici de la virtut que reclama és per tal que el

${ }^{23}$ Ed. cit., pàg. 174 , part II, paràgr. 4.

${ }^{24}$ Ibidem, pàg. 169, és el paràgr. 10.

${ }^{25}$ És clar que Llull té en compte virtuts pròpiament cavalleresques com la generositat, la noblesa de coratge, la lleialtat... que un cavaller podia fer seves perquè ja eren en el seu sistema moral, molt més simple que el que se li oferia des de posicions eclesiàstiques. A la part VI del llibre, el que fa el beat és aplicar a la cavalleria les virtuts teologals i les cardinals: fe, esperança, caritat, justícia, prudència, fortitudo, temprança. 
cavaller exerceixi unes funcions que li són pròpies $\mathrm{i}$ la societat segueixi l'ordenament que Déu li ha donat.

El Blaquerna, en canvi, presenta un perfeccionament moral de l'individu molt més immediat i general. Seria fals negar que a la novel.la Llull no faci referència també a una reforma social basada en els oficis en què la societat ha estat dividida; el passatge més interessant es posa en boca de l'ermità Blaquerna a la fi del llibre:

Mas en temps som venguts que quaix home no husa de la final entenció per què los uficis foren començats al començament; cor lo començament de clergues fo fundat sobre bona entenció en primer, e açò mateix se segueix dels cavallers, juristes, artistes, metges, merchaders, religioses, ermitans e tots los altres uficis; mas ara som en temps sdevenguts que, cor hom no'n husa tan fort com deuria, de la entenció per què los uficis e les sciències són, per açò és lo món en error e treball, e Déu és innorat, desamat, desobeït, per aquells qui són obligats a amar, e conèixer, e obeir e servir Déu. ${ }^{26}$

Però al llarg del Blaquerna es parla sobretot d'una ètica i una moral generals, que afecten la vida dels homes més enllà de l'ofici que exerceixen. La cavalleria i la clerecia coincideixen en què són oficis, encara més, en què són ordes; però la diferència prové del fet que el beat escriu un llibre en què considera la clerecia al costat del matrimoni: vol referir-se, doncs, als estats de vida, i el matrimoni comprèn tots els oficis menys la clerecia. Aquella distinció gregoriana a què he fet referència, des del seu origen, es proposa de situar el religiós per sobre dels altres estaments, especialment el cavalleresc, ja que la tripartició funcional no ho fa explícitament.

${ }^{26}$ Vol. III, pàgs. 179-180. A continuació d'això Blaquerna encarrega a un joglar que difongui oralment el Romanç d'Evast e Blaquerna «en lo qual són significades les rahons per les quals foren atrobats los començaments demunt dits» (pàg. 180). Crec que hem d'entendre que l'obra tracta de tots aquests oficis com a novel-la total que pretén ser (i que és), on apareixen tots els estaments, tots els homes, totes les situacions... i on es narra la reforma de tota la cristiandat; és a dir, de forma implícita. 
He fet un petit excurs per arribar al que plantejava al començament. Crec que Llull en dir «cor nós avem a perlar del llibre qui és de l'orde de clerecia» no enuncia un títol sinó un tema; anuncia un llibre que tractarà sobre la clerecia. Tradicionalment s'ha cregut que aquest Llibre de l'orde de clerecia havia de tenir una estructura i un contingut equivalents als del Llibre de l'orde de cavalleria (només cal recordar el que deia $\mathrm{M}$. Obrador), potser perquè al tractat sobre la cavalleria s'estableixen nombrosos paral-lelismes entre els dos ordes. Tanmateix, és prou coneguda la capacitat d'innovació del beat: només tenim un Blaquerna, un Llibre del gentil, un Llibre de meravelles, un Arbre de filosofia d'amor. Potser hom esperava que al llibre sobre la clerecia completés una de les parts del sistema trifuncional esbossat al tractat sobre la cavalleria. Sembla que el projecte del beat no anava per aquí. ${ }^{27}$

Ara bé, ambdues obres es relacionen per la preocupació social que demostren, i per la insistència d'ambdues en la regeneració moral dels individus com a via de reforma de la societat. El Blaquerna explicita en alguna ocasió la necessària ètica professional que s'ha de retornar als oficis, idea que és fonamental al Llibre de l'orde de cavalleria. D'altra banda, l'estructura del Blaquerna i la concepció de la societat que s'hi exposa (que engloba tots els homes), acosta el llibre a una gran diversitat de receptors; probablement, Llull l'adreça a tothom que tingui uns hàbits de lectura similars: clergues, cavallers, la resta de la societat. L'opuscle sobre la cavalleria té uns receptors concrets i determinats, els cavallers i tot aquell que pugui tenir part en la seva formació. Si Llull hagués escrit un Llibre de l'orde de clerecia, en forma de tractat sobre la vida, els costums, les funcions i la dignitat de l'orde (que completés

${ }^{27}$ Potser, de fet, el problema era el tercer orde. Els laboratores a final del segle XIII és ja un conjunt tan bigarrat i complex com apareix al Blaquerna. Com definir aleshores una ètica concreta que fos vàlida per a burgesos, menestrals, pagesos, pastors, assalariars? 
l'esquema trifuncional), els receptors haurien estat també exclusivament els clergues.

Tanmateix, després del Llibre de l'orde de cavalleria va escriure la Doctrina pueril (ambdues obres entre $1274-1276$ ), i sembla que van transcórrer uns deu anys entre l'opuscle sobre els cavallers i el final de la novel-la. A la doctrina d'infants, el Blaquerna ja apareix citat amb totes les lletres; això segurament indica que l'havia començat a escriure. ${ }^{28}$ Què va passar amb el seu projecte durant aquests anys?

$\mathrm{Ja}$ he dit que la referència al final de l'opuscle sobre els cavallers potser només indica un tema, un llibre només vagament projectat. La formulació del títol al final de la Doctrina pueril assenyala segurament que la novella ja estava comença$\mathrm{da}$; fins i tot podria ser un indici d'una obra amb dues parts més o menys simètriques sobre els laics i els clergues, Evast $e$ Blaquerna. La dilació i la lenta concreció de l'obra fins a l'any I 283 expliquen les diferències estructurals que hom registra entre una part i una altra, especialment entre la IV i V i la resta. Potser a mesura que la història de Blaquerna creixia i el personatge prenia força, el projecte inicial del llibre de clerecia esdevenia la vasta novel.la "total», mosaic de tots els homes, atractiva il-lusió de reforma de tota la societat, que avui llegim. ${ }^{29}$

${ }^{28}$ A la Doctrina pueril, Llull esmenta el tractat sobre els cavallers; ho fa en un capítol sobre els clergues i, de fet, excusant-se de no parlar de la cavalleria: "Enaixí com lo comensament de cavalaria fo per mantenir justícia, segons que ya havem parlat en lo Libre de l'borde de cavalleria, enaxí (...)" R. Llull, Doctrina pueril, Barcelona, ENC, 1972, pàg. 190. Al final de la doctrina d'infants parla del Blaquerna: «On pus te parle, fill, de la celestial glòria, més trop en mi de defalliment a recomptar e a significar la glòria de paradís, e per açò lexar-me n'é, e parlarem del Libre de Evast e de Blanquerna», pàg. 243. Són remarcables, en aquest sentit, els paral-lelismes entre el cap. 9 I de la Doctrina, sobre l'alimentació dels infants, i l'episodi que s'explica al principi del Blaquerna, ed. cit., vol. i, pàg. 32 .

${ }^{19} \mathrm{~L}$ a variació en el títol de la novel la, que al començament parla de llibre i al final de romanç (també en els manuscrits francesos es fa aquesta distinció), pot 
La redacció, doncs, es devia aturar diverses vegades per motius que, és clar, desconeixem. Durant la primera meitat de I276, quan ja havia escrit la Doctrina pueril, va ser fundat el col-legi de missioners de Miramar. ${ }^{30}$ Aquesta institució havia d'absorbir per força el beat, almenys els anys següents. Fins i tot, pel que fa a l'obra escrita, la seva atenció havia de centrar-

ser indicativa del lapse temporal que hi ha hagut entre el seu inici i el seu acabament. Jordi Rubió havia indicat això, però com indici d'una possible «refosa de l'obra", ja que es declarava cautelosament partidari d'una doble redacció; veg. Història de la literatura catalana, vol. I, Montserrat, 1984, pàg. 1or. La tesi que propugna dues redaccions del Blaquerna s'ha basat sempre en la pretesa similitud de la història del protagonista amb la dimissió del dissortat Celestí V (desembre de 1294). Qui ha desenvolupat més extensament aquesta tesi és A. Caimari, "Notes» a R. Llull, Libre de Evast... op. cit., vol. IV, pàgs. 67-73. No sóc el primer a trobar molt remota la semblança entre la ficció $i$ la realitat; en canvi, les variacions en l'estructura de l'obra (i d'altres detalls) poden ser arguments de molt més pes per postular una construcció de l'obra en dos temps. Donat que hi ha raons importants per no situar la data més enllà de 1283 (veg. nota 2), podem explicar aquestes variacions estructurals per la duració de l'escriptura de la novel.la: de 1276 a 1283 .

${ }^{\circ}$ Per aquesta qüestió veg. S. Garcías Palou, El Miramar de Ramon Llull, Palma, I977, cap. V. Al capítol LXXXIII de la Doctrina pueril, el beat es queixa: «Molt sant religiós és desiyós a morir per honrar la passió de Déu, e per salvació de son proïsme, e apendrà, si era qui li amostrás, lo lenguatge, e irà preÿcar la paraula de Déu, si era qui.l tramesés; mas no és qui fassa monestirs establitz a diverses lenguatges ha apendre, ne no és qui.ls frares trametrà», ed. cit. pàg. 195-196. En canvi, al Blaquerna esmenta el col-legi i diu: «Aquell rey [Jaume II] és bé acostumat e ha devoció com per preycació fos honrat Jesu Crist enfrèls infeels; e per açò ha ordenat que xiii- frares menors studien en aràbich en un monestir apellat Miramar, apartat, asegut en loch cuvinable, e a'ls provehits a lurs necessitats; e com sabran l'aràbich, que vagen honrar, per licència de lur general, lo fruyt de nostra Dona, sustinents, per honrar aquel, fam, set, calt, fret, temors, turments e mort. E aquest stabliment és fet per tots temps", vol II, pàgs. 57-58. La referència apareix a la segona part del llibre de religió, al «Llibre d'Ave Maria", quan Blaquerna ja és abat. Adonem-nos: el que Llull havia escrit de la novel.la en acabar la Doctrina pueril i abans de la fundació de Miramar ha de ser anterior a aquest passatge; la novel-la, en aquest punt, és encara un llibre que tracta de laici i clerici amb una extensió similar. 
se en textos que poguessin aplicar-se més immediatament al curriculum de l'escola. Hem de tenir en compte que per Llull una novel.la era sempre un instrument secundari de divulgació; en aquests anys va escriure d'altres obres que ell devia considerar molt més importants i que podien interrompre el Blaquerna. D'altra banda, no és sobrer recordar que aquells van ser uns temps de grans $\mathrm{i}$ inquietants esdeveniments a la Corona d'Aragó: mort de Jaume I, partició del regne, vespres sicilianes, croada contra Catalunya, Jaume II perd les Balears però reté Perpinyà i Montpeller... ${ }^{3 x}$

És potser una suposició arriscada. En qualsevol cas, em fa l'efecte que el Blaquerna no és una obra escrita d'una tirada, seguint un pla previ estricte, sinó un llibre tortuós que s'ha anat modificant. Aquella lectura capil-lar a què em referia encara està bàsicament per fer. D'altra banda les tres obres que he esmentat repetidament, i també el Llibre d'intenció, reflecteixen un període en què Llull es preocupa per la societat, des de diversos punts de vista. Revelen una inquietud que ja apareixia de forma sintètica al Llibre de contemplació i que després es desenvolupa de manera molt més detallada i específica. ${ }^{32}$

${ }^{31}$ En aquest sentit ha afirmat F. Domínguez: «A continuació [de la Doctrina pueril] va començar el llibre d'Evast e Blaquerna, que va acabar el 1283 . Comptant amb les possibles interrupcions d'aquest, a causa, entre d'altres coses, de la seva estimada empresa de Miramar, no hi ha dubte que de vuit a deu anys per escriure un llibre és quelcom d'inconcebible en Ramon Llull. El llibre de Blaquerna és, en tot cas, una obra escrita amb calma en el silenci î recer adquats, sense presses ni concessions", «El Libre d'amic e amat. Reflexions entorn de Ramon Llull i la seva obra literàriaw, a Randa, vol. 19, Barcelona, 1986, pàg. 122 . A. Santamaría, Ramon Lull y la Corona de Mallorca, Palma, 1989, pàgs. 22-32, fa un repàs interessant a aquests esdeveniments històrics $i$ la seva influència en Llull; n'assenyala un possible ressò al Blaquerna que a mi em sembla molt poc significatiu.

${ }^{32}$ Vegeu, com a exemple, l'anàlisi que faig sobre el canvi en el concepte de cavalleria del capítol CXII del Llibre de contemplació al Llibre de l'orde de cavalleria. "Mas cavaller qui d'açò fa lo contrari». Una lectura del tractat lul-lià sobre la cavallerian, a Estudios lulianos, vol. 29, 1989, pàgs, 109-117. 
Aquestes obres, doncs, s'han de llegir també de forma comparativa.

Per això, acabaré esmentant un passatge de la Doctrina pueril que suggereix l'interès que té la via d'estudi aquí encetada sobre els esquemes de la societat en l'opus lul-lià:

Ubligat és, fill, en ésser en orde de matrimoni o religió, cor tot altre estament se desconvé ab la final intenció per la qual és creat. ${ }^{33}$

ALBERT SOLER I LLOPART UNIVERSITAT DE BARCELONA

${ }^{33}$ Ed. cit., pàg. 87. 